\title{
Reliability determination of aluminium electrolytic capacitors by the mean of various methods. Application to the protection system of the LHC
}

\author{
F. Perisse ${ }^{\mathrm{a}}, \mathrm{P}$. Venet $^{\mathrm{b}}, \mathrm{G}$. Rojat $^{\mathrm{b}}$ \\ ${ }^{\text {a }}$ LEA Boulevard Marie \& Pierre CURIE - Teleport 2 BP 30179, F86962 Futuroscope, France \\ ${ }^{\mathrm{b}}$ CEGELY UCB Lyon 1, Bat Omega,Domaine universitaire de la Doua 69622 Villeurbanne, France
}

\begin{abstract}
The lifetime of power electronic components is often calculated from reliability reports, but this method can be discussed. We compare in this article the results of various reliability reports to an accelerated ageing test of component and introduced the load-strength concept. Large aluminium electrolytic capacitors are taken here in example in the context of the protection system of LHC (Large Hadron Collider) in CERN where the level of reliability is essential. We notice important differences of MTBF (Mean Time Between Failure) according to the reliability report used. Accelerating ageing tests carried out prove that a Weibull law is more adapted to determinate failure rates of components. The load-strength concept associated with accelerated ageing tests can be a solution to determine the lifetime of power electronic components.
\end{abstract}

\section{Introduction}

The choice of the components in power electronics is guided by two principal parameters. First is commonplace, it relates to the rated values which is requested by the operation of the system. The second relates to reliability and is subject to discussion. Indeed, reliability depends on many parameters, it is difficult to evaluate in many cases. Currently the reliability of components is in the majority of the cases determined from reliability reports resulting from statistical results. We can quote for example the following reports:

- MILL HDBK 217F [1]

- Rdf 93, Rdf $2000[2,3]$

- Telcordia [4]

- 299B share Stress [5]

- HRD5 [6].
In this article, we propose to compare results from the reliability reports with results from accelerated ageing test. We describe also a righter approach of named load-strength concept.

We take as example aluminium electrolytic capacitors. These components are used by CERN (European Organization for Nuclear Research) in power supply "quench heaters" used for the protection of the superconductive magnets of the LHC (Large Hadron Collider) [7]. As the electrolytic capacitors constitute the weak point of power supply $[8,9,10]$ their choice is of primary importance for the reliability of the LHC. The numbers of power supplies is 6000 ; the system thus comprises 36000 capacitors whose reliability is quite necessary. 


\subsection{Components and protection system studied}

The components used in this study are large aluminium electrolytic capacitors of rated values $\mathrm{C}_{\mathrm{R}}=4700 \mu \mathrm{F}, \mathrm{U}_{\mathrm{R}}=500 \mathrm{~V}$ and temperature range $-40^{\circ} \mathrm{C}$, $85^{\circ} \mathrm{C}$. We show in figure 1 the geometry of various components studied. Components produced by different manufacturers with the same rated values can have very different levels of reliability.

These differences are due to the technological parameters adopted by the manufacturers [10].

For example, we noted catastrophic failures related to:

- anode corrosion due to the intrusion of halogenous ions ( $\mathrm{D}$ components)

- internal overpressures due to the geometry of the components ( $\mathrm{E}$ and $\mathrm{F}$ components)

- breakdown due to the connection of the tabs on the terminals (A components)

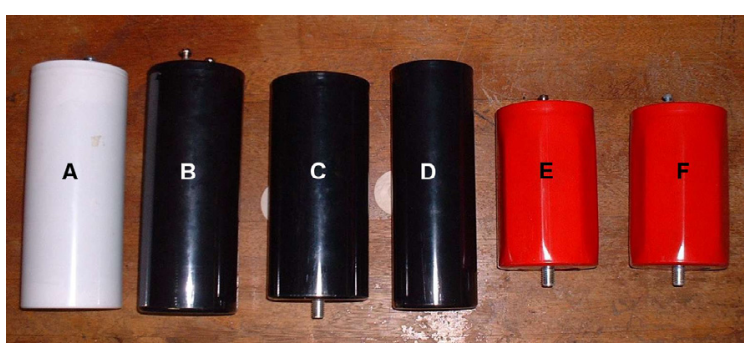

Fig. 1. Capacitors studied

The protection of the superconductive magnets is guaranteed when the energy which is accumulated in the capacitors reached $1.8 \mathrm{~kJ}$ [11]. This energy is

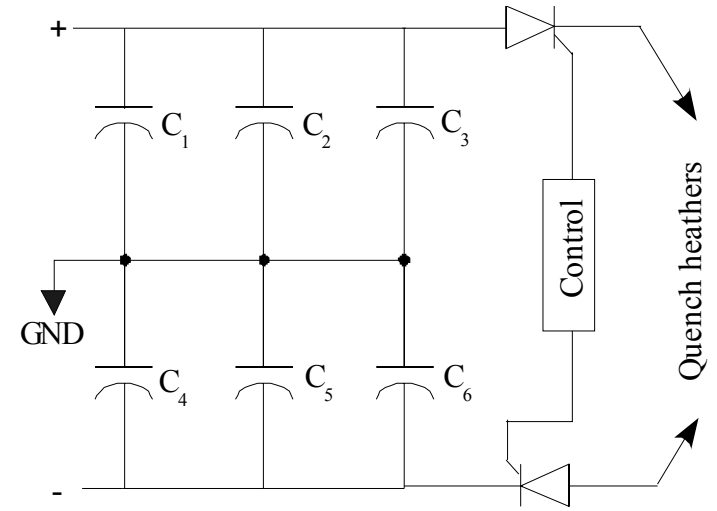

Fig. 2. General diagram of power supply transmitted to the protection system via two thyristors (1800V - 80A) (see Fig. 2). The operating conditions are $450 \mathrm{~V} \mathrm{DC}$ and an ambient temperature of $20^{\circ} \mathrm{C}$.

The six capacitors can store an maximum energy of $2.85 \mathrm{~kJ}$. Thus, the system can accept the failure of one or more capacitors according to the failure mode considered (short or open circuit).

We study two cases of failure:

- Case $n^{\circ} 1$ : Failure of the capacitors by shortcircuit.

- Case $n^{\circ}$ 2: Failure of the capacitors by open circuit.

\section{Normative approach}

It consists of the use of reliability reports previously quoted. Calculations of failure rate are based on the characteristics of the components and on their way of use. For example, we show in table 1, principal parameters necessary to calculate failure rate of electrolytic capacitors for various reliability report.

Then, we carry out the calculation of the MTBF of the power supply according to two failure configurations (Case $n^{\circ} 1$ and Case $n^{\circ} 2$ )

\subsection{Calculation of failure rates}

The individual failure rates of capacitor and thyristor are defined in FIT (Failure In Time $=1$ faillure $/ 10{ }^{9}$ hours). The results are calculated for different reliability reports for 6000 power supplies and are defined by the use of MTBF (see. fig. 3).

We note significant differences between the reliability reports. These differences can partly be explained by the matter of fact that they privilege more or less some influence factors [12]. The diversity of these results confirms the importance of accelerated ageing test under the conditions which are close to the mission profile of the system.

\section{Accelerating aging test, statistical approach}

The principal cause of breakdown of electrolytic capacitors is a progressive failure. It is due to the timedependent evaporation of the electrolyte.

The lifetime of these components depends on the criterion chosen to define it. The parameter, which is varying more during ageing time of this component, is equivalent series resistance (ESR). The variation of this parameter is considered as the criterion of end of 
Table 1

Principal parameters of various reliability reports

\begin{tabular}{|c|c|c|c|c|c|c|c|}
\hline \multirow[b]{2}{*}{ Reliability reports } & \multicolumn{7}{|c|}{ Principal parameters } \\
\hline & $\begin{array}{c}\text { Capacitor } \\
\text { type }\end{array}$ & Capacitance & $\begin{array}{c}\text { Quality } \\
\text { level }\end{array}$ & Voltage & Current & Temperature & Mission profile \\
\hline MIL-HDBK-217 FN2 & $\mathbf{X}$ & $\mathbf{X}$ & $\mathbf{X}$ & $\mathbf{X}$ & & $\mathbf{X}$ & \\
\hline RDF 93 & $\mathbf{X}$ & & $\mathbf{X}$ & $\mathbf{X}$ & $\mathbf{X}$ & $\mathbf{X}$ & \\
\hline Telcordia & $\mathbf{X}$ & $\mathbf{X}$ & $\mathbf{X}$ & $\mathbf{X}$ & & $\mathbf{X}$ & \\
\hline 299 B Part Stress & $\mathbf{X}$ & & $\mathbf{X}$ & $\mathbf{X}$ & $\mathbf{X}$ & $\mathbf{X}$ & \\
\hline HRD5 & $\mathbf{X}$ & & $\mathbf{X}$ & & & $\mathbf{X}$ & \\
\hline RDF 2000 & $\mathbf{X}$ & & & $\mathbf{X}$ & $\mathbf{X}$ & $\mathbf{X}$ & $\mathbf{X}$ \\
\hline
\end{tabular}

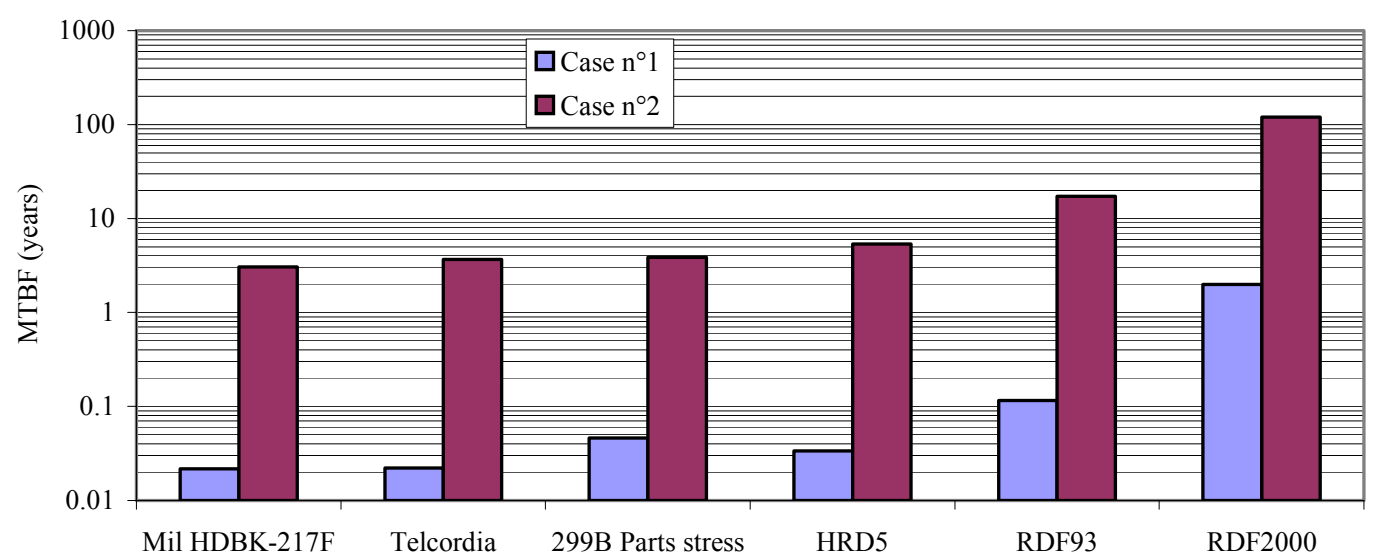

Fig. 3 MTBF of 6000 power supplies for different reliability reports.

lifetime $[8,10,11]$. The increase allowed in the ESR depends on the application in which the component is used. We take a limit, which is defined by a multiplication by factor two of the ESR at $100 \mathrm{~Hz}$.

There are many failure laws possible to describe the lifetime of a system or a component. We use the exponential law, the Weibull law and normal law in order to determine their distribution functions of failure and to compare them. These various laws are characterized by their function of probability density $f(t)$. From $f(t)$ it is possible to determine the failure distribution function $F(t)$. The relationship between these two functions and the failure rate $\lambda$ versus time are defined by [14]:

$$
\begin{aligned}
& F(t)=\int_{0}^{t} f(t) d t \\
& \lambda(t)=\frac{f(t)}{1-F(t)}
\end{aligned}
$$

These functions are described in equation 3 to 11 for different distribution laws.

\subsection{Exponential law}

Probability density function:

$$
f(t)=\lambda \cdot \exp (-\lambda . t)
$$

Failure distribution function:

$F(t)=1-\exp (-\lambda . t)$

Failure rate:

$\lambda(t)=\lambda$

\subsection{Weibull law}

Probability density function:

$f(t)=\frac{\beta}{\eta} \cdot\left(\frac{t-\gamma}{\eta}\right)^{\beta-1} \cdot \exp \left(-\left(\frac{t-\gamma}{\eta}\right)^{\beta}\right)$ when $t \geq \gamma(6)$

Failure distribution function:

$$
F(t)=1-\exp \left(-\left(\frac{t-\gamma}{\eta}\right)^{\beta}\right) \text { when } t \geq \gamma
$$


Failure rate:

$$
\lambda(t)=\frac{\beta}{\eta} \cdot\left(\frac{t-\gamma}{\eta}\right)^{\beta-1} \text { when } t \geq \gamma
$$

$\beta, \quad \gamma, \eta$ are coefficients dependent on the components studied.

\subsection{Normal law}

Probability density function:

$$
f(t)=\frac{1}{\sigma \cdot \sqrt{2 \cdot \pi}} \cdot \exp \left(-\frac{1}{2} \cdot \frac{(t-\mu)^{2}}{\sigma^{2}}\right)
$$

Failure distribution function:

$$
F(t)=\int_{-\infty}^{t} \frac{1}{\sigma \cdot \sqrt{2 \cdot \pi}} \cdot \exp \left(-\frac{1}{2} \cdot \frac{(t-\mu)^{2}}{\sigma^{2}}\right) \cdot d t
$$

Failure rate:

$$
\lambda(t)=\frac{\exp \left(-\frac{1}{2} \cdot \frac{(t-\mu)^{2}}{\sigma^{2}}\right)}{\int_{t}^{\infty} \cdot \exp \left(-\frac{1}{2} \cdot \frac{(t-\mu)^{2}}{\sigma^{2}}\right) \cdot d t}
$$

$\mu$ and $\sigma$ are coefficients dependent on the components studied.

The failure distribution $F(\mathrm{t})$ and the failure rate which is deduced from these various distribution laws are represented in figures 4 and 5 .

The most precise failure distribution function is the normal law. However this normal law induces a reduction in the failure rate after a certain ageing time.

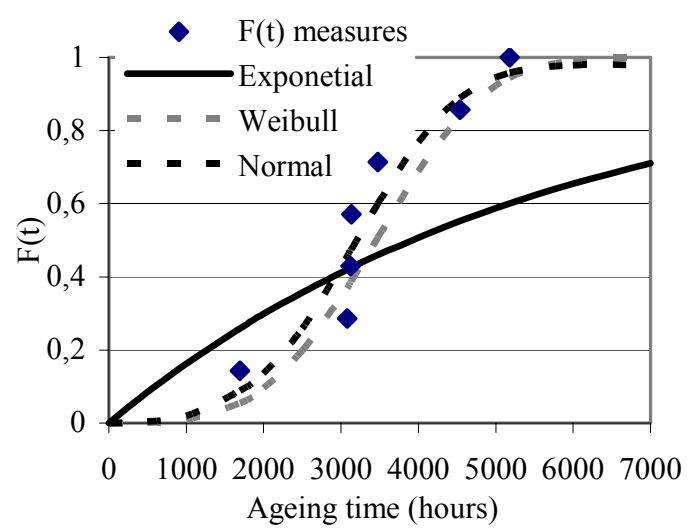

Fig. 4. Failure distribution versus time.

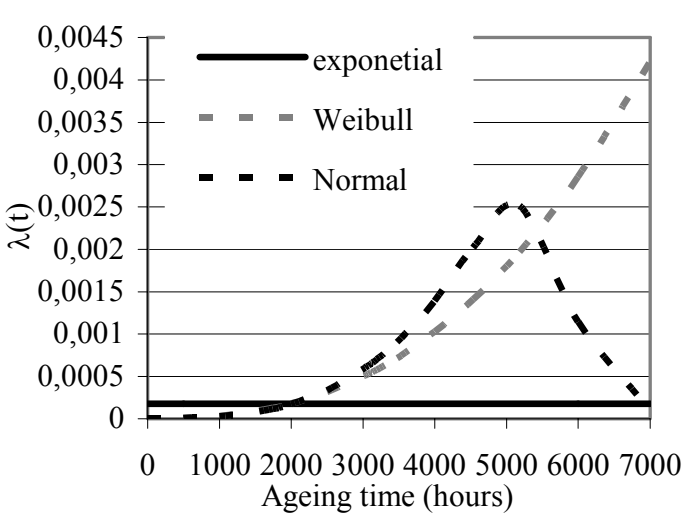

Fig. 5. Failure rate versus time

The real ageing of an aluminium electrolytic capacitor is not represented in this way. $T$ he exponential law considers a constant failure rate. This failure rate does not represent the wear-out period. The most appropriate reliability law is the Weibull law.

\section{Approach to load-strength}

This approach is based on the energy storage concept originally introduced into reliability engineering by Haviland $[13,15]$. We detail below the basis of this healthy components concept.

A component or a part stores energy when a load is applied. This energy can be electrical, thermal, mechanical one. The energy, which is stored in the component, is the stress, which is induced by the load and the environment. This stress can be compared to the maximum strength the component can support.

\subsection{Capacitor example}

We consider three cases. In the first case the load is represented by the voltage applied to the component, in the second case by the temperature, and in the last case by the energy stored in the component. In all cases we represent the load according to a normal distribution law.

- $1^{\text {st }}$ case: the load of the component is defined by $450 \mathrm{~V} \pm 10 \%$ voltage. The manufacturers define the maximum strength as $115 \%$ of rated voltage i.e. $575 \mathrm{~V}$.

- $2^{\text {nd }}$ case: the load is defined by environment temperature. The maximum strength is $85^{\circ} \mathrm{C}$ and load 
is a normal distribution whose average is equivalent to the applied ambient temperature of $20^{\circ} \mathrm{C}$.

- $3^{\text {rd }}$ case: the load applied is defined by stored energy $\mathrm{E}$ for one capacitor. It is function of the supply voltage and the rated capacity of the component which is $4,7 \mathrm{mF}$. The maximum strength depends on rated values $\mathrm{C}_{\mathrm{R}}=4700 \mu \mathrm{F}$ and $\mathrm{U}_{\mathrm{R}}=500 \mathrm{~V}$.

Figure 6 to 8 shows the load and the maximum strength for these three cases.

A safety factor $S F$ can be deduced. $S F$ represents the separation of the load and the maximum strength [15]:

$$
S F=\frac{\bar{S}-\bar{L}}{\sqrt{\sigma_{S}^{2}+\sigma_{L}^{2}}}
$$

Where:

- $\bar{S}$ : mean value of the strength $=$ maximum strength in our case.

- $\sigma_{S}:$ standard deviation of the strength distribution $=0$ in our case.

- $\bar{L}$ : mean value of the applied load

- $\sigma_{L}$ : standard deviation of the load distribution

\subsection{Ageing effect}

The component ageing induces the decrease of the maximum strength value. In order to guarantee reliability, make sure that there is no overlapping of the load diagram and strength curve (maximum strength in our cases). If there exists any overlapping the failure probability due to this one can be determined.

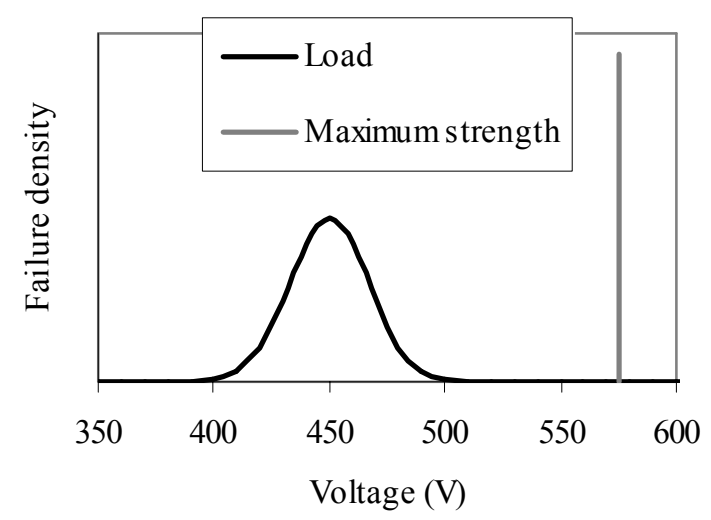

Fig 6. Distribution of failure density versus voltage

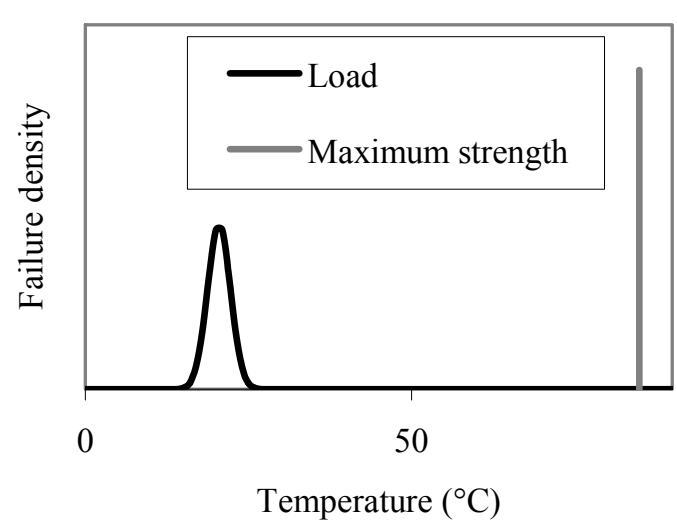

Fig. 7. Distribution of failure density versus temperature

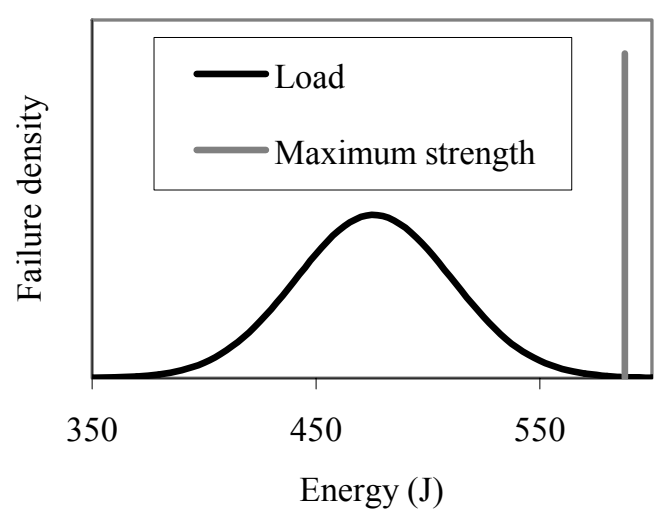

Fig. 8. Distribution of failure density versus energy

\section{Conclusion}

The use of reliability reports can be discussed. Indeed the results are very different according to the reliability reports. Moreover they do not take account of the technological differences according to various manufacturers $[10,11]$. We showed that the calculation of failure rate by the use of exponential law is too approximate. The use of Weibull law is better. The load-strength concept associated with accelerated ageing tests can be a solution to determine the lifetime of power electronic components. 


\section{Acknowledgements}

We thank the CERN represented by Mr. Felix Rodriguez-MATEOS and Mr. Reiner DENZ which allowed, by a profitable collaboration the realization of this work.

\section{References}

[1] U.S. MIL SPECS, "Military Handbook Reliability Prediction of Electronic Equipment, MIL-HDBK217F", note 1: July 1992, note 2: February 1995.

[2] Centre National d'Etudes des Télécommunications, "Recueil de données de fiabilité des composants électroniques RDF93", UTE C 80-819, 1993.

[3] Union Technique de l'Electricité et de la communication, "Recueil de Données de Fiabilité : RDF 2000. Modèle universel pour le calcul de la fiabilité prévisionnelle des composant, cartes et équipements électroniques", UTE C 80-810, 2000.

[4] Bellcore (Telcordia) standards TR-332 Issue 6 and SR332 Issue 1 (published by AT\&T Bell Labs).

[5] Chinese Military Standard, China 299B (GJB/z 299B).

[6] British Telecommunications, reliability standard HRD5.

[7] Evans L R, "The LHC Project ", 17th Magnet Technology Conference, Geneva, September 2001, Proceedings.
[8] P. Venet, "Monitoring of power converter. Application to predictive maintenance ", Thesis of University Claude Bernard Lyon1, France 1993

[9] Mr. L Gasperi, "Life Prediction Model for Aluminium Electrolytic Capacitors", IEEE IAS Conference, 1996, pp. 1347-1351.

[10] F Perisse, P. Venet, J.M. Retif, G Rojat "Behavioral Study one the Reliability of Electrolytic Capacitors of Various Manufacturers" European Safety and Reliability Conference (ESREL 2002), Conference European of Reliability $(\lambda \mu 13)$ Lyon France, 2002, pp. 632-636.

[11] F Perisse, "Study and Analyses of Failure Modes of the Electrolytic Capacitors and Thyristors, Applied to the protection of the LHC (Large Hadron Collider)", Thesis of Université Claude Bernard Lyon1, France 2003.

[12] Jones J Hayes J, "A Comparison of ElectronicReliability Prediction Models", IEEE transaction one Reliability, vol. 48, N2, June 1999, pp 127-134

[13] R.P. Haviland, "Engineering Reliability and Long Life Design", van Nostrand, Prineton 1964.

[14] Klass B Klassen, Jack C.L. van Peppen, "System Reliability, Concept and Applications", First published in Great Britain 1989, ISBN 0-340-50142-1. pp 51-53

[15] F. Jensen, "Electronic Component Reliability", John Wiley \& Sons Ltd, 1996. 